EESTI NSV TEADUSTE AKADEEMIA TOIMETISED 1952. I k. nr. 1 ИЗВЕСТИЯ АКАДЕМИИ НАУК ЭСТОНСКОЙ ССР 1952. ТоМ I, № 1

\title{
ОКИСЛЕНИЕ СЛАНЦЕВ КАК МЕТОД ИССЛЕДОВАНИЯ ХИМИЧЕСКОЙ ПРИРОДЫ КЕРОГЕНА
}

\author{
П. К. КОГЕРМАН, \\ действительный член Академии Наук Эстонской ССР
}

Неравномерность распределения месторождений нефти и природного газа на огромной территории Советского Союза, а местами и их отсутствне на обширных пространствах страны, обуславливает необходимость компенсировать эту неравномерность созданием промышленности искусственного жидкого топлива и газа, использующей местные виды твердого топлива, в частности горючие сланцы.

Внимание, уделяемое нашей партией, правительством и лично товарищем Сталиным развитию сланцевой промышленности прибалтийского бассейна, обязует работников науки и производства напрягать все усилия для усовершенствования старых и внедрения новых методов переработки горючих сланцев.

Предпосылкой для рационального использования горючих сланцев в интересах народного хозяйства является всестороннее изучение их химической природы.

Несмотря на значительное количество научных работ, появившихся за последние десятилетия и связанных с проблемой сланцев, до сих пор еще нет ни общепринятого научного определения, ни единой научно обоснованной химической классификации этих горючих ископаемых.

Геологи хотя и обогатили литературу по горючим ископаемым терминами вроде анабитума, катабитума и других битумов, все же эти термины не имеют пока точного химического смысла.

Классификация каустобиолитов А. Ф. Д о б р я н с к о г о, основанная на химическом анализе обширного и многообразного материала, является крупным вкладом в науку и заслуживает глубокого изучения их всеми научными работниками, исследующими горючие ископаемые $\left({ }^{4,5}\right)$. Также заслуживает внимания классификация С. М. Г р и г о р ве в а $\left(^{3}\right)$.

В результате критического анализа всего опубликованного материала по горючим сланцам, А. Ф. Добрянский $\left({ }^{4,5}\right)$ и др. пришли к заключению, что в природе существует много разновидностей битума или керогена сланцев; к этому заключению пришел и автор на основании свонх исследований $\left({ }^{15}\right)$. По химической природе и условиям седиментации органического вещества сланцы следует классифицировать по нескольким типам, в зависимости от характерных, химических свойств их керогена.

Кероген не является определенным химическим соединением, но, вероятно, представляет смесь многих высокомолекулярных органических соединений. Этот термин обозначает органические вещества сланцев, кото- 
рые при перегонке превращаются в смолу и газ. Никаких минеральных масел или смолы в готовом виде горючие сланцы не содержат, и кероген практически не растворим в большинстве органических растворителей, Термином «битум» обычно обозначают ту часть органической массы твердых горючих ископаемых, которая растворима в сольвентах, хотя некоторые авторы и не придерживаются этой демаркационной линии.

Кероген является высокомолекулярным веществом и при его исследовании следует использовать богатый опыт химии больших молекул.

Отсутствие достаточных данных о химической природе керогена до сих пор препятствовало и препятствует выработке научной химической классификации сланцев.

По мнению некоторых исследователей, горючие сланцы занимают промежуточное положение между углями и нефтью и имеют некоторые общие черты как с каменным углем, так и с нефтью $\left({ }^{13}\right)$.

Геологи относят наши кукерситные сланцы к автохтонным битуминозным породам ордовиция (нижнесилурийские отложения).

При выяснении генезиса сланцев возникают три проблемы: 1) какова природа материнского вещества, из которого образовались сланцы; 2) каковы условия седиментации органического вещества и минеральных веществ, входящих в золу и 3) как преобразуется органическое вещество после осаждения до стадии керогена. Последний процесс часто называют $б$ и т у м н и 3 а ц и ей, но, ввиду вышеприведенных определений и дифференции понятий битум и кероген, его следовало бы назвать к е р оге и и з а ци е й.

Под микроскопом, в тонких шлифах, большая часть органического вещества горючих сланцев представляется в виде желтых прозрачных телец, которые своими характерными очертаниями иногда напоминают микроводоросли, но чаще в виде бесформенной желтой массы. Такие желтые образования встречаются в сланцах, относящихся к весьма различным геологическим эпохам, и дают при перегонке первичные смолы различного химического состава $\left({ }^{15}\right)$. Многие геологи считают эти желтые шарики растительными смолами и пытаются найти зависимость между содержанием растительных смол и коэффициентами смолообразования при перегонке сланцев, т. е. они считают, что чем больше желтых телец в сланце, тем выше выход первичной смолы при расчете на кероген.

В случае кукерситных сланцев геологи и палеоботаники пытались идентифицировать подобные скопления желтых телец с микроводорослями $\left({ }^{17}\right)$. Однако по мнению А. Ф. Добрянского роль синезеленых водорослей в образовании керогена сильно преувеличена $\left({ }^{4}\right)$. В связи с образованием керогена заслуживают внимания работы Е. И. Қазакова о химическом составе планктона и сапропелей $\left({ }^{7}\right)$.

Если теория образования кукерсита из альг обоснована, то остается исследовать еще два процесса: 1) седиментацию этих микроводорослей совместно с минеральным веществом и 2) послеседиментационные превращения органического вещества. Последняя проблема весьма актуальна и интересна для биохимика, химика-органика, а также и для технологасланцевика, поскольку процесс керогенизации определяет химическую природу органического вещества сланцев.

Биогеохимической лабораторией Академии Наук СССР собран обширный материал по химическому составу микроорганизмов планктона $\left({ }^{1}\right)$. Сопоставление данных, полученных в упомянутой лаборатории, с анализом керогена обнаруживает резкие расхождения между составом материнского вещества микроводорослей и керогеном сланцев и указывает на глубокие химические превращения в процессе керогенизации.

Из новейших работ Биогеохимической лаборатории заслуживают вни- 
мания исследования А. П. Виноградова и Е. А. Бойченко о пектиновых веществах в древних породах. Нашим советским ученым удалось обнаружить пектины даже в кукерсите, но гемицеллюлозы и клетчатки им открыть не удалось $\left({ }^{2}\right)$.

Открытие пектиновых веществ в кукерсите является веским доводом в пользу альгийной теории происхождения наших сланцев, хотя оно и противоречит существующим литературным данным. Г. Л. Стадников в своей книге «Происхождение углей и нефти» пишет $\left({ }^{13}\right):$ « природе пектиновые вещества подвергаются гидролическому расщеплению при действии ферментов - пектазы и пектиназы; в результате такого расщепления получаются легкорастворимые в воде сахары, из которых пентозы могут быть унесены водой из мест скопления остатков растительных организмов, а гексозы могут быть сброжены, если путем конденсации с продуктами распада белков они не успевают превратиться в нерастворимые меланоидиныж.

В пользу растительного происхождения горючих сланцев говорят еще исследования Трейбса $\left({ }^{13}\right)$, который спектрофотометрическим методом обнаружил порфирины в некоторых сланцах (в количестве от 0,004 до $0,0004 \%)$. Но так как по нахождению хлорофилла в листьях нельзя еще судить о химической природе самого листа или стебля, то и открытие порфиринов в сланцах еще не раскрывает тайны химической структуры керогена.

Ввиду нерастворимости керогена в большинстве нейтральных растворителей, непосредственный химический анализ его затруднен и приходится применять косвенные методы исследования, как-то действие теплоты и реактивов, заведомо глубоко нзменяющих структуру органических веществ, образующих кероген.

Я. И. Хисин и М. М. Лейвикова $\left({ }^{14}\right)$, изучившие кинетику термического разложения сланцев, пришли к выводу, что разложение гдовских сланцев, близких к кукерситу, имеет характер мономолекулярной реакции, другими словами, кероген этих сланцев состоит из немногих соединений.

Перегонка кукерсита в глубоком вакууме как будто подтверждает это предположение, а именно, интервал кипения смолы, полученной в вакууме, гораздо у́же пределов кипения первичной сланцевой смолы, получаемой при атмосферном давлении.

В данной статье автор ограничивается лишь описанием одного метода исследования сланцев, применение которого к изучению природы каменного угля дало весьма важные результаты, а именно, метода окисления сланца-кукерсита перманганатом калия в щелочном растворе. Несмотря на то, что эта реакция вызывает глубокие превращения органических веществ, образующих кероген, все-таки на основании имеющегося обширного экспериментального материала, по аналогии с протеканием той же реакции в случае чистых органических соединений, можно вывести неко. торые общие заключения о природе керогена.

Линденбейн ${ }^{\left({ }^{17}\right)}$ впервые систематически исследовал продукты окисления кукерсита по методу Шульце, применяя для окисления смесь $\mathrm{KClO}_{3}$ и конц. $\mathrm{HNO}_{3}$. В зависимости от подготовки пробы, от температуры и продолжительности окисления он наблюдал три стадии реакции. Первую реакцию он проводил с обогащенной пробой кукерсита, содержащей $4,5 \%$ золы. После 48 часов окисления при температуре водяной бани образовался желты й р а ссып ч т ы й порошок, содержащий еще $2,85 \%$ золы. Состав окнсленного чистого органического вещества: $\mathrm{C}-51,78 \%, \mathrm{H}-5,94 \%, \mathrm{~N}-1,80 \%, \mathrm{O}-40,50 \% ; \mathrm{C} / \mathrm{H}=8,63$. Несомненно, параллельно с окислением происходило нитрование части органиче- 
ского вещества керогена. Желтая масса при высушивании (около $100^{\circ} \mathrm{C}$ ) набухала и плавилась с выделением газа с прогорклым запахом.

Для второго опыта кукерсит был обработан ледяной уксусной кислотой, удалившей большую часть золы, которой оставалось всего $16,6 \%$. При проведении окисления теми же окислителями при температуре водяной бани наблюдалось быстрое обесцвечивание продукта. После 48-часовой реакции получился б е ц в е тн й порошок, который в высушенном и растертом виде напоминал белую муку. Элементарный состав органической части: $\mathrm{C}-35,37 \%, \mathrm{H}-2,47 \%, \mathrm{~N}-0,73 \%$ и $\mathrm{O}+\mathrm{S}-61,43 \%$; $\mathrm{C} / \mathrm{H}=14$.

Наконец, для третьего опыта брали уже обработанный уксусной кислотой сланец и дополнительно обрабатывали его HF для удаления оставшейся золы. Эту пробу почти чистого керогена в течение недели нагревали на водяной бане с теми же окислителями. К концу реакции кукерсит терял свою структуру, плавился и был похож на амебовидную массу.

Органическое вещество после окисления было отфильтровано, промыто; на фильтре осталась желтая с зеленоватым оттенком с л и 3 и с т а я м а с с а, имевшая следующий состав: $\mathrm{C}-35,14 \%, \mathrm{H}-4,62 \%, \mathrm{O}-$ $60,24 \%$; оно не содержало ни азота, ни серы.

Все три продукта окисления не имели определенной точки плавления: при температуре $100^{\circ}$ они размягчались, около $160^{\circ}$ набухали и превращались в смолу. Никаких индивидуальных соединений не было выделено.

Әти опыты, между прочим, доказывают, что предварительная обработка кукерсита концентрированными кислотами, даже уксусной кислотой, изменяет химическую природу керогена, так как все три продукта окисления отличались друг от друга не только физическими свойствами, но и элементарным составом.

Боном и его сотрудниками $\left({ }^{16}\right)$ был разработан в двух вариантах метод окисления горючих ископаемых щелочным раствором перманганата калия, а именно: первый вариант, названный «методом баланса углерода», и второй вариант, названный «валовым окислением».

Отличаются эти варианты тем, что при первом варианте к кипящей смеси прибавляют 3,5-процентный раствор $\mathrm{KMnO}_{4}$, а во втором случае к кипящей смеси прибавляют порциями кристаллический перманганат. Первый метод можно было бы назвать также аналитическим методом; второй вариант вызывает более глубокое окисление, т. е. образование в результате вторичной реакции $\mathrm{CO}_{2}$ за счет кислот, образующихся в первой стадии окисления. Вызываются эти вторичные процессы излишками периодически прибавляемого перманганата. В лаборатории Бона было исследовано этим методом несколько десятков органических соединений, а также торф, бурые и каменные угли.

Сводка результатов некоторых из упомянутых исследований вместе с нашими данными по окислению керогена приведена в таблице 1.

По данным таблицы 1 видно, что при окислении перманганатом 11 методу Бона целлюлоза давала кроме воды и $\mathrm{CO}_{2}$ еще щавелевую кислоту. Присутствие бензолкарбоновых кислот в продуктах окисления целлюлозы не удалось доказать. При окислении торфа, бурого и каменного углей образовались, кроме упомянутых соединений, т. е. $\mathrm{CO}_{2}$ и $(\mathrm{COOH})_{2}$, еще бензолкарбоновые кислоты, причем количество их возрастало с геологическим возрастом упомянутых ископаемых.

Кислоты, образующиеся при окислении кукерсита, по химическому составу отличаются от бензолкарбоновых кислот, и мы рассмотрим их детальнее ниже.

В. А. Ланин и М. В. Пронина $\left({ }^{10}\right)$ получили при окислении органического вещества гдовского сланца большие количества $\mathrm{CO}_{2}$ и кислоты: 
Продукты окисления целлюлозы, яигнина и некоторых горючих ископаемых (По методу жбаланса углерода»)

\begin{tabular}{|c|c|c|c|c|c|c|c|}
\hline \multirow[b]{2}{*}{$\%$ С в виде: вещества } & \multirow{2}{*}{ 竞 } & \multirow[b]{2}{*}{ Лигнин } & \multirow[b]{2}{*}{ Торф } & \multirow[b]{2}{*}{$\begin{array}{l}\text { Бурый } \\
\text { уголь }\end{array}$} & \multirow{2}{*}{$\begin{array}{c}\text { Камен- } \\
\text { ный } \\
\text { уголь }\end{array}$} & \multicolumn{2}{|c|}{ Кероген кукерсита } \\
\hline & & & & & & $\begin{array}{c}\text { Окислен- } \\
\text { ная } \\
\text { часть }\end{array}$ & $\begin{array}{l}\text { На весь } \\
\text { кероген }\end{array}$ \\
\hline $\begin{array}{l}\text { (1) } \mathrm{CO}_{2} \\
\text { (2) } \mathrm{CH}_{3} \mathrm{COOH} \\
\text { (3) } \mathrm{COOH}-\mathrm{COOH} \\
\text { (4) Бензолкарбоновая }\end{array}$ & $\begin{array}{r}47,0 \\
1,0 \\
48,8\end{array}$ & $\begin{array}{c}57-60 \\
2,7-6,0 \\
21-22\end{array}$ & $\begin{array}{c}49-61 \\
3,1-5,6 \\
15-18\end{array}$ & $\begin{array}{c}45-57 \\
3,0-7,5 \\
9-23\end{array}$ & $\begin{array}{c}36-42 \\
1,7-4,6 \\
13-14\end{array}$ & $\begin{array}{r}47,0 \\
1,0 \\
43,4\end{array}$ & $\begin{array}{r}42,3 \\
0,9 \\
39,1\end{array}$ \\
\hline $\begin{array}{l}\text { кислота } \\
\text { (5) Нелетучие кислоты, } \\
\text { кроме перечисленных } \\
(2)(3),(4) \\
\text { Отношение (4), (3) }\end{array}$ & $=$ & $0,5-0,75$ & $0,65-0,9$ & $1,5-2,0$ & $39-46$ & $\stackrel{8,6}{-}$ & 7,7 \\
\hline $\begin{array}{r}\text { acxo } \\
\text { веш }\end{array}$ & $|0,98|$ & 1,45 & 1,16 & $24-1,5$ & $1,48-1,65$ & $2,4-2,9$ & 2,2 \\
\hline
\end{tabular}

уксусную, щавелевую и янтарную; бензолкарбоновые кислоты в продуктах окисления отсутствовали.

В общих чертах состав продуктов окисления кукерсита как будто напоминает продукты окисления целлюлозы, но в продуктах окисления целлюлозы отсутствуют высшие нелетучие кислоты, характерные для продуктов окисления кукерсита.

Резкое отличие обнаруживается в расходе кислорода, необходимого для окисления; для целлюлозы и гуминовых кислот на 1 г вещества для окисления до $\mathrm{CO}_{2}$ и $\mathrm{COOH}-\mathrm{COOH}$ требуется $1-1,2$ г О , а в случае кукерсита $-2,2 \mathrm{\Gamma} \quad \mathrm{O}_{2}$. Следовательно, химическая природа керогена сильно отличается от целлюлозы, а также и от гуминовых веществ, несмотря на некоторые общие продукты окисления.

Н. А. Орлов и О. А. Радченко $\left({ }^{12}\right)$ изучали самоокисление кукерсита на воздухе, в термостате при $105^{\circ}$, в течение 231 суток. Для опытов служил кукерсит, содержание золы в котором путем механической обработки и разложения карбонатов 3-процентной $\mathrm{HCl}$ было снижено до $17 \%$. После 231 суток нагревания слабая щелочь извлекала из выветрившегося кукерсита $75 \%$ бурых веществ, которые авторы считают гуминовыми веществами. После осаждения кислотой, тщательной промывки и высушивания при умеренной температуре было получено вещество следующего состава:

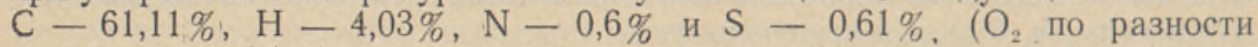
составлял $33,65 \%$ ).

Кислотный эквивалент оказался равным 422.

Смесь полученных кислот была окислена по Бону перманганатом в течение 26 часов.

В продуктах окисления исследователи нашли: 1) уксусную кислоту $3,7 \%$, муравьиную кислоту - $0,3 \%$, а остальные кислоты были переведены в смеси серебряных солей, содержащих 59,3\% серебра. По аналогии с содержанием серебра в бензол-дикарбоновых и трикарбоновых кислотах, исследователи заключают о присутствии в продуктах окисления выветрившегося кукерсита бензолкарбоновых кислот. Кроме того, качественно была обнаружена орто-фталевая кислота.

В результате описанных опытов авторы пришли к заключению, что *изучение продуктов выветривания кукерсита дает возможность сделать заключение о весьма большой их близости к другим гуминовым кислотам». 
К. Лутс $\left({ }^{11}\right)$ указывал на глубокие изменения в природе керогена, вызываемые нагреванием кукерсита в термостате в атмосфере воздуха. После 408 часов нагревания при $105^{\circ} \mathrm{C}$ процентное содержание углерода и водорода в керогене сильно снизилось, а именно до $\mathrm{C}-62,8 \%$ и $\mathrm{H}-$ $4,7 \%$. Выход смолы из окисленного керогена значительно уменьшился и составлял лишь $9,6 \%$, причем удельный вес жидкого дестиллата был 0,78 .

Состав бурого вещества, полученного Н. А. Орловым и О. А. Радченко, близок к составу частично окисленного керогена, исследованного Лутсом, но вряд ли следует эти вещества отнести к гуминовым.

Если бы при искусственном выветривании кукерсита образовалось такое значительное количество гуминовых веществ, как предполагают Н. А. Орлов и О. А. Радченко, то образования их следовало бы ожидать и при других методах окисления, а также и при нитровании. Между тем другие исследователи не обнаружили при окислении керогена гуминовых веществ. При действии азотной кислоты на шведские сланцы было получено значительное количество так называемых «нитросланцевых кислот», которые можно отнести к гуминовым кислотам, а продукты реакции кукерсита с $\mathrm{HNO}_{3}$ не содержали «нитросланцевых кислот», а следовагельно и гуминовых веществ. Продукты нитрования керогена кукерсита более напоминают нитролаки, чем гуминовые кислоты.

В нашей лаборатории старшим научным сотрудником И. К. Первиком и другими была исследована кинетика реакции керогена кукерсита по методу окисления его перманганатом калия в щелочном растворе, а также были проанализированы продукты этой реакции.

При первой серии опытов мы придерживались условий первого варианта метода Бона, упомянутого выше, а затем, при дальнейших наших опытах, мы видоизменили методику Бона. Во-первых, мы исследовали скорость реакции окисления в зависимости от температуры (в пределах $20-100^{\circ}$ ) и концентрации гидроксильных ионов, во-вторых, определили количество перманганата, необходимого для окисления, а также возможность окисления керогена воздухом при $90^{\circ} \mathrm{C}$, в-третьих, проводили реакцию окисления по ступеням.

При температуре $80^{\circ} \mathrm{C}$ в течение первых трех часов происходит бурная реакция. Если же провести реакцию при температуре $20^{\circ} \mathrm{C}$, то полное окисление керогена длится свыше 120 часов. Для опытов брали обогащенный сланец с $16 \%$, золы.

Анализ данных, полученных по методу Вант-Гоффа, указывает на то, что реакция окисления керогена перманганатом калия соответствует реакции второго порядка: $\mathrm{K}_{2}=0,00197$ при $80^{\circ} \mathrm{C}$ (см. табл. 2).

Таблица 2

Константы скорости окисления 20 г обогащенного сланца в $1 \%$ растворе $\mathrm{NaOH}$ при $80^{\circ}$

\begin{tabular}{c|c|c|c}
\hline $\begin{array}{c}\text { Время } \\
\text { мин. }\end{array}$ & $\begin{array}{c}\text { Использо- } \\
\text { вано } \\
\text { КМпО }_{4}\end{array}$ & $\kappa_{\mathbf{2}}$ & $\mathrm{K}_{\mathbf{1}}$ \\
\hline 20 & 2,21 & 0,00221 & \\
45 & 3,30 & 0,00179 & 0,01134 \\
60 & 3,88 & 0,00179 & 0,01026 \\
90 & 4,66 & 0,00174 & \\
120 & 5,30 & 0,00181 & \\
150 & 5,90 & 0,00202 & 0,00836 \\
180 & 6,21 & 0,00134 & \\
300 & 7,00 & 0,00225 & \\
480 & 7,57 & 0,00278 & \\
& среднее & 0,00197 &
\end{tabular}


В случае неполного окисления керогена получается в качестве промежуточного продукта черное вязкое вещество, напоминающее вар. При полном окислени кероген дает почти бесцветную кристаллическую массу кислот. При окислении кукерсита по нашему методу, даже при избытке $\mathrm{KMnO}_{4}$, часть керогена, около $9 \%$, не окисляется, т. е. остается нерастворимой. При окислении по методу Бона не растворяется до $36 \%$ керогена, что указывает на вторичные реакции конденсации.

В настоящей статье не дано подробного описания опытов окисления, а приведены только результаты наших опытов. Как было упомянуто выше, даже при ступенчатом окислении только $90 \%$ керогена кукерсита превращается в растворимые кислоты. В этой смеси кислот доминирует щавелееая кислота, количество которой составляет примерно половину всех кислот. Наиболее интересными являются нелетучие кислоты, кроме щавелевой.

На окисление 16,8 г керогена потребовалось 38,6 г кислорода. При половинном количестве перманганата или кислорода получается неполный продукт окисления в виде черного пека. Почти половина этого вещества растворима в эфире $(\mathrm{A})$, остальная же часть легко растворяется в ацетоне (Б). Часть, растворимая в ацетоне (Б), не перегоняется без разложения даже при 9 мм Hg, но часть, растворимая в эфире (A), перегоняется в атмосфере азота при 9 мм $\mathrm{Hg}$ давления без разложения.

Әлементарный состав части $\mathrm{A}: \mathrm{C}-58,19 \%, \mathrm{H}-7,95 \%$, кислотное число 422,4 .

Әлементарный состав части Б: С $-58,93 \%, \mathrm{H}-8,04 \%$, кислотное число 245,7 .

Иодные и ацетильные числа обенх фракций равны нулю.

Данные о составе фракций, перегоняющихся без разложения (A), приведены в таблице 3 .

Характеристика фракций из части А

\begin{tabular}{|c|c|c|c|c|c|c|}
\hline Номера фракций & I & II & III & IV & V & Ост аток \\
\hline 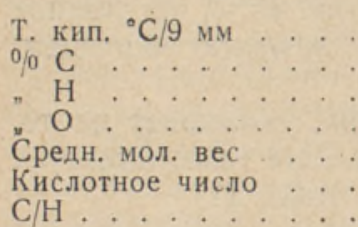 & $\begin{array}{c}185-210^{\circ} \\
52,75 \\
6,76 \\
40,49 \\
193,3 \\
586 \\
7,8\end{array}$ & $\begin{array}{c}210-230^{\circ} \\
56,64 \\
8,04 \\
35,32 \\
197,4 \\
569 \\
7,0\end{array}$ & $\begin{array}{c}230-248 \\
58,16 \\
8,27 \\
33,57 \\
236,6 \\
474 \\
7,0\end{array}$ & $\begin{array}{c}255-270^{\circ} \\
61,14 \\
8,51 \\
30,35 \\
316,9 \\
354 \\
7,2\end{array}$ & $\begin{array}{c}270-280^{\circ} \\
62,90 \\
8,90 \\
28,20 \\
370,3 \\
303 \\
7,0\end{array}$ & $\begin{array}{r}280^{\circ} \\
70,94 \\
8,22 \\
20,84 \\
- \\
\overline{8,4}\end{array}$ \\
\hline
\end{tabular}

Средний состав смеси кислот (кроме $\mathrm{CO}_{2}$ и $\mathrm{COOH}-\mathrm{COOH}$ ) из керогена $\mathrm{C}_{9} \mathrm{H}_{16} \mathrm{O}_{4}-\mathrm{C}_{16} \mathrm{H}_{28} \mathrm{O}_{6}$ Средний состав смеси кислот (кроме $\mathrm{CO}_{2}$ и $\mathrm{COOH}-\mathrm{COOH}$ ) из угля $\mathrm{C}_{9} \mathrm{H}_{6} \mathrm{O}_{6}-\mathrm{C}_{10} \mathrm{H}_{6} \mathrm{O}_{8}$ С/H бензолкарбоновых кислот из углей $18-20$

Қак видно из таблицы 3 , состав высших кислот, полученных из керогена кукерсита, не отвечает составу бензолкаробоновых кислот. Состав некоторых фракций отвечает составу алифатических кетоновых или лактоновых кислот. Исследования в этой области еще продолжаются.

Сотрудники Бона подвергли окислению свыше 60 типичных органических соединений алифатического, ароматического и гетероциклического рядов.

Из этого богатого опытного материала нас интересуют главным образом те соединения, которые при перегонке могут давать производные ароматического ряда, но при окислении не дают бензолкарбоновых кислот, как это наблюдается в случае окисления кукерсита. Оказывается, что производные бензола, содержащие в качестве субституентов группы, в 
составе которых имеется кислород, как-то: конифериловый альдегид и 1-метил-2-альдо-метокси-бензол-диетил-ацеталь, а также кумарон (продукт қонденсации бензола с фураном), легко окисляются до $\mathrm{CO}_{2}$ и щавелевой кислоты, причем других кислот не образуется.

В качестве интересного примера приводим исследования в области растительных пигментов, которые показывают, что каротиноиды, например, $\boldsymbol{\alpha}$-каротин, при термическом разложении дают ароматические соединения, а при окислении перманганатом калия только кислоты жирного ряда. Интересно отметить, что отношение C/H в каротине отвечает таковому в керогене кукерсита и что каротин для окисления до $\mathrm{COOH}-\mathrm{COOH}$ требует 2,1 г кислорода на 1 г вещества. Каротин находится также в синезеленых и диатомовых водорослях и легко адсорбируется крупнозернистой углекислой известью. Каротиноиды, как непредельные соединения, в случае перехода в кероген, вероятно, полимеризовались и частично окислялись, превращаясь в нерастворимые поликаротиноиды.

Е. И. Казаков установил присутствие каротина в ряде сапропелей от 5 до 20 мг в 100 г сухого вещества $\left({ }^{8}\right)$.

Критический анализ всех литературных данных по окислению органических соединений и сопоставление их с данными наших опытов по окислению кукерсита, исследования кинетики окисления и процесса окисления по ступеням уже на нынешней стадии развития научных исследований позволяют исключить громадное количество органических соединений из сферы нашего внимания и сузить до незначительного числа звеньев цикл тех соединений, которые образуют кероген наших сланцев. В состав керогена кукерсита входят по крайней мере три группы органических соединений: А - дающая при окислении жирные кислоты или их производные со средним кислотным числом 422, Б - дающая при окислении жирные, а при предварительном искусственном выветривании, возможно, и бензолкарбоновые кислоты со средним кислотным числом 246, и, в-третьих, часть, которая в условиях опыта не окисляется до растворимых кислот. Оставшуюся от окисления нерастворимую часть керогена образуют, по всей вероятности, полициклические соединения, вроде ретена, труксена и др., которые в условиях наших опытов не окисляются. Возможно, что эти соединения образовались при процессе окисления в результате поликонденсации, так как количество остатка зависит от температуры опыта.

Можно надеяться, что нашим советским ученым, верным научным традициям Менделеева, Бутлерова и других корифеев русской и советской науки, закаленным в трудовых подвигах под знаменем Ленина Сталина, удастся в ближайшем будущем развязать гордиев узел тесно переплетающихся углеродистых соединений, образующих кероген сланцев, и тем самым заложить прочную основу новой отрасли науки б и о ш и с т л о г и и - науки о горючих сланцах.

\section{ЛИТЕРАТУРА}

1. А. Г!, В и ног радов, Химический элементарный состав организмов моря, ч. 1 и 2. Тр. Биохим, лабор. АН СССР, тт. III и IV.

2. А. П. Виног ра дов и Е. А. Бо й ч ен ко, Состав клеточных оболочек современных и ископаемых низких организмов, Доклады АН СССР, т. ХХXIX, № 9, 1943.

3 C. $\mathrm{M}$. Г р и го р ье в, Қлассификация горючих ископаемых и их технические свойства, Сборник «Энергетическое совещание по горючим сланцам Әстонской ССР , 1948.

4. А. Ф. Д о б р я н с к и й, Горючие сланцы СССР, Гостоптехиздат, 1947, стр. 160 и сл.

5. А. Ф. Д о 6 р ян с к и й, Геохимия нефти, Гостоптехиздат, 1948, стр. 395.

6. П. И. Д у бысов и П. В. Ч елин це в, Сборник жГорючие сланцы и их техническое использованиеж, ОНТИ, 1932, стр. 267. 
7. Е. И. К а за ков, Химико-технологическая характеристика сапропелей СССР, Тр. лабор. генезиса сапропеля ИГИ АН СССР, вып. 2, 1941, стр. 81-85.

8. Е. И. К а з а к о в, О каротине в сапропеле. Там же, стр. 53-59.

9. А. В К о же в н и ко в, Горючие сланщы I, Тарту, 1947, стр. 3 и 23.

10. В. А. Л а н и н и $М$. В. П рон и н а, Об органическом веществе горючих сланцев, Изв. АН СССР, ОТН, № 10/11, 1944.

1i. К. Л у т с, Журн. «Горючие сланцы», № 1, 1935, стр. 62.

12. Н. А. О р ло в и О. А. Р ад ч е н ко, Выветривание кукерсита, Ж. П. Х., 1934, стр. $1476-1479$.

13. Г. А. С т а дн и к о в, Происхождение углей и нефти, 1937 , стр. 546 и др.

14. Я. О. Х и с и н и М. М. Л е й в и к о в а, Кинетика термического разложения сернистых сланцев, Журн. «Горючие сланцы», № 1, 1935.

15. P. Kog e rma n, The Chemical Nature of Estonian Oil-Shale. Annales Societatis Rebus Naturae Investigandis in Universitate Tartuensi constituae, XXXIV, 2, 1927.

16. W. A. B on e, L. G. B. Parsons, R. H. Sapiro and C. M. Groocock, Researches on the Chemistry of Coal, VIII, Proc. Roy. Soc. A. vol. 148, nr. 865, 1935.

17. H. A. R. Li n de n be i n, La kuckersite, Archives des Sciences physicques et naturelles, vol. $3,1921$. 